\title{
Governance Path of Rural Gambling Prevailing in the Context of Rural Revitalization Strategy
}

\author{
Zhang Jiejie, Huang Yixuan \\ Shaanxi Normal University
}

\begin{abstract}
The problem of rural gambling has a long history. Many scholars have carried out a lot of analysis on its causes and ways of governance, but most of them are based on legal construction and propaganda, which cannot solve the problem fundamentally. From the perspective of sociology, this paper takes the $X$ village of Wenzhou as a specific example, combines the strategy of Rural Revitalization and uses the literature analysis and participatory observation as the main research method, to discuss the reasons for the prevalence of gambling in rural areas from four aspects of geographical location, income sources, infrastructure construction and cultural construction. This paper puts forward a solution from the rural economy, culture, infrastructure construction and grass-roots teams. It hopes to effectively solve the prevalence of gambling in $\mathrm{X}$ village and eliminate backward gambling culture, so as to provide reference for rural gambling.
\end{abstract}

Keywords-Rural gambling; Rural Revitalization; Gambling atmosphere; Gambling governance

\section{INTRODUCTION}

Chairman $\mathrm{Xi}$ put forward the strategy of Rural Revitalization in the nineteen major reports of the Communist Party of China. The strategy of Rural Revitalization is the latest achievement of the continuous development and innovation of the "three rural" strategy in China. It needs to adhere to the priority development of agricultural and rural areas, establish and improve the system mechanism and policy system of urban and rural integration development in accordance with the general requirements of industrial prosperity, ecological livability, rural wind civilization, effective governance and rich life, and promote the rural economy as a whole. Construction, political construction, cultural construction, social construction, ecological civilization construction and Party construction will accelerate the modernization of rural governance system and governance capacity, accelerate the modernization of agricultural and rural areas, take the road of revitalizing the socialist countryside with Chinese characteristics, make agriculture a running industry, and make farmers attractive [1].
There are many difficulties in the development of Rural Revitalization Strategy, one of which is the hindrance of gambling culture. Gambling has been popular in China for thousands of years. Gambling in a narrow sense refers to profitable gambling, which constitutes a crime of gambling, and gambling in a broad sense includes all kinds of gambling related entertainment, which is not for profit. With the development of society, the form of gambling has been constantly changing, and gambling money has been increasing, attracting all kinds of people to indulge in it. The prevalence of this unhealthy trend has had a great negative impact on individuals, families, society and the state. People indulge in gambling, in order to gamble and win money by unscrupulous means, the event that offends the bottom line of the law has occurred, which not only leads to a large number of families broken, but also seriously endangers the public security and the interests of the citizens. After the founding of new China, the state has made a series of laws and regulations on gambling, and has made a series of laws and regulations. However, the phenomenon of gambling is still common, especially in some remote rural areas, which is still in vogue.

In recent years, the academic research achievements of gambling are plentiful, especially in the management of rural gambling atmosphere, but on the whole, this kind of research is mainly from the perspective of law, mainly involved in the analysis of the reasons for the prevalence of gambling, the analysis of the adverse effects of gambling and the related countermeasures to eliminate gambling vogue, and so on. Most of the countermeasures are from the legal level of improving the relevant laws and regulations, increasing the strength of the attack, strengthening the publicity of the rule of law and so on, and less comprehensive discussion of the combination of economic and cultural aspects. In the existing academic research achievements, from the perspective of sociology, the research results of gambling are less, mainly focusing on the causes and Countermeasures of individual gambling behavior. This paper, from the perspective of sociology, combined with the policy of rural revitalization, focuses on the overall rural development, analyzes the prevailing phenomenon of gambling in the village of $X$ in the city of Wenzhou, and explores the reasons and ways of governance, trying to find the best solution to the prevailing governance of the rural gambling atmosphere and the realization of the Revitalization Strategy of the rural village. 


\section{THE DESCRIPTION OF X VILLAGE IN WENZHOU}

The village of $\mathrm{X}$ is located in the northeast mountain area of Wenzhou. The village is remote, the village is surrounded by mountains and the traffic is closed. The resident population is about 200 people. Most of them are middle-aged unemployed and left behind old people. The main economic source is still the traditional agricultural product sales income, and still maintains the self-sufficient agricultural habits. The villagers' daily recreational activities are rare, mainly listening to the play and gambling. Because of the high demand for the equipment and the low frequency of the opera to the countryside, gambling becomes the most common recreational activity of the villagers. In order to meet the needs of gambling, the villagers will be converted from the ancestral hall into an elderly activity room as one of the main gambling venues. In addition, the villagers in the home to open the gambling point is not in the minority, dozens of households in $1 / 3$ of the villagers have gambling points, $90 \%$ of the villagers' regular gambles. Their daily gambling activities last longer, except for busy farming and free time, almost all are occupied by gambling activities. In addition to the children in the village, almost everyone will gamble, and take this as the main way to send the time, during the festival, it is more popular, is the famous "gambling village" in the county.

\section{REASON}

\section{A. Geographically closed}

First, $\mathrm{X}$ village is located in remote mountainous area with remote geographical location, inconvenient transportation and backward transportation facilities. It is isolated from the outside world for a long time and has little radiation impact in the surrounding central towns. Therefore, the village is still in a relatively backward self-sufficient life state, and its economic source almost entirely depends on traditional agricultural production. Too close an objective environment provides a stable environment for the spread and maintenance of gambling behavior and the prevalence of gambling. Because of the lack of the impact of external culture, gambling culture continues to continue in daily behavior. In addition, the closeness and inconveniences of the geographical environment have made the management of the $\mathrm{X}$ village incompetent, and the unhealthy tendencies are ungoverned, and even a lot of grass-roots cadres are also involved in the daily gambling behavior, becoming one of the driving forces of the prevailing gambling atmosphere, making the grass-roots organizations more small on gambling behavior.

Secondly, the closed and backward objective environment hinders the communication between the villagers and the outside world to a certain extent. They lack the way of perceiving, accepting new things and new culture, and lack the understanding of the correct values and the cognition of the advanced culture, which leads to the backwardness and stubbornness of the villagers' thoughts and the lack of understanding and understanding of the harm of gambling. The ability to accept and adapt to the new culture is weak.

\section{B. The source of income is single}

The village of $\mathrm{X}$ has a unique planting condition, and the development conditions of agriculture and forestry industrialization are good. However, because of the large number of migrant workers go out for a job, the labor force in the village is seriously insufficient and the existing resources of the X village cannot be fully utilized. The demand for the living resources of the permanent residents in the village is low, the simple planting industry can be satisfied, and the support of the children of the migrant workers, so that they can guarantee their own life, and even have some surplus without the need of a large amount of work. With the economic income substitution effect, with the increase of the wage rate, workers get the same income in less working hours. Therefore, when the wage rate increases, workers' working hours are reduced, which is one of the important reasons for the villagers' lack of labor enthusiasm. Survival data are easy to satisfy, leisure time is greater than labor time, and more funds left at hand can be used to help gambling.[2]

\section{Backwardness in infrastructure construction}

The construction of traffic facilities is insufficient. Only two roads are connected with the outside world. The roads are narrow and the lighting conditions are poor. The communication signal is weak, and the population gathering area still takes the horn and public telephone as the main way of contact. Backward transportation and communication facilities restrict people's ability to acquire information, and thus affect people's cultural acceptance and cultural creativity.

The village is lack of educational resources. It has in $80 \mathrm{~s} \mathrm{a}$ primary school, but due to the constraints of the family economic conditions, not every villager can be given the opportunity to receive education, so that the level of knowledge of the present aged and middle-aged villagers is uneven. With the outflow of population, primary schools were forced to close down in 90s, which led to the low level of education for young villagers. The low level of education has limited the ability of the villagers in all aspects, especially in the comprehension ability, which makes the effect of legal knowledge speaking, illegal behavior popularization, especially gambling harm propaganda, and also restricts the villagers' understanding and acceptance of excellent culture, and limits them to the culture of gambling. China has been unable to extricate itself from gambling quagmire and encourage gambling, which has hindered the implementation of Rural Revitalization Strategy.

The backwardness and insufficient quantity of infrastructure construction have seriously affected the construction of rural wind and the prevailing gambling atmosphere, and gambling has made villagers unenterprising, inadvertently put into production and development, worsened the local economic development conditions, and thus hindered the development of Rural Revitalization and formed a vicious circle. 


\section{The backwardness of cultural construction}

Wenzhou requires rural grass-roots organizations to vigorously carry out rural cultural construction, establish rural community cultural activities center, excavate and protect the traditional cultural resources, inherit folk traditional handicraft culture, and create rural culture. However, the construction of cultural activities center in $X$ village has not been implemented, the related cultural infrastructure is scarce, and there is no place for the villagers to carry out cultural and recreational activities in the day-to-day agricultural production activities. The lack of screening equipment, as well as the lack of new technical means, made the traditional traditional culture of the traditional opera culture of $\mathrm{X}$ a great resistance. Although the activities of the countryside in the countryside have been held year by year, but only one year can only take turns. The supply of cultural products does not meet the rich and colorful cultural and entertainment needs of the villagers. The demand for cultural market in rural areas is very large, but the actual supply of culture is very short. In reality, only one kind of gambling behavior can be chosen, which makes gambling become more and more difficult.

\section{COUNTERMEASURES}

\section{A. Develop the characteristic economy}

The prosperity of the industry is one of the general requirements for the revitalization of the countryside. The economic growth brought by the industrial development is the material prerequisite for the revitalization of the rural culture. $\mathrm{X}$ village has a more than $1000 \mathrm{mu}$ agricultural base, which can develop the characteristic agriculture with the form of livable farm music. It can also make use of the unique natural conditions, establish precious orchid cultivation base, and develop the flower industry. With the development prospects and policy support, the village can provide a large number of employment opportunities and attract migrant workers to go home to develop. Adequate labor is also conducive to the development of agricultural industrialization and the economic vitality of agriculture and other industries. It can solve the problem of unsustainable development of resources in villages and enrich the daily life of idle labor in villages, and reduce the time of their dues in gambling. The return of the younger generation also enriched the spiritual life of the middle-aged and old people, so that they could feel that they were old enough to enjoy their family happiness and not to rely on gambling to pass the time.

\section{B. Increase the supply of cultural products}

The lack of cultural life in rural areas is an important reason for the prevalence of gambling. Therefore, it is one of the important solutions to develop the rural culture and meet the needs of the villagers' culture. The closed geographical conditions of $X$ village make the rich and excellent socialist advanced culture difficult to spread and develop. This requires a large amount of government to increase the supply of rural cultural public products and increase the introduction and publicity of excellent culture. The county and township level two government should actively implement the policy proposed by the municipal government to build the rural cultural activity center, ensuring that the rural culture can be supported by space and can be developed in an objective environment. It is far from enough to ensure the protection of the hardware conditions, actively organizing the activities of the excellent culture to the countryside, increasing the supply of cultural products, improving the quality of the supply of cultural products, expanding the range of excellent cultural radiation, enriching the amateur cultural life of the villagers, spreading the excellent culture of the villagers and encouraging the villagers to carry out various kinds of cultural learning. We should strive to build villager culture with distinctive characteristics and actively guide villagers to make cultural creation. We should truly implement rural wind construction, create civilized villages and villages, and provide spiritual guarantee for Rural Revitalization.

\section{Improve the construction of infrastructure}

"Ecological livability" is one of the major prerequisites for completing the five demands of Rural Revitalization. A good living environment, a perfect infrastructure configuration and a comprehensive life guarantee are the objective basis for promoting rural transformation and self development. It will attract outflow personnel back to the village, promote the transformation and upgrade of the rural industrial structure, and enrich the farmers. The cultural undertakings of the village all have a positive role to promote.

We should make full use of the existing two necessary transportation routes, repair mountain roads, fix mountainside talc, repair steps, and increase armrest, so as to improve mountain road safety. Making full use of the scenery along the way to create a sightseeing and easy climbing path is one of the natural conditions for developing the characteristic farmhouse music. At the same time, we should improve the construction of the county road, widen the road surface, install the street lamp, slow down the sharp bend and so on, and provide logistics support for the orchid planting industry by improving the traffic and transportation conditions. Open the rural bus routes near the countryside to facilitate the villagers to travel. By strengthening the communication and communication between the villagers and the outside world, widening their vision, improving the villagers' acceptance of the outside world, reducing the idle time, and reducing the trend of the prevailing trend of gambling.

In view of the fact that the population of the village is mostly middle-aged and old, the level of knowledge is low, the education of middle and old age should be fully developed, the old universities and the communication activities of middle and old age should be set up to improve the cultural level of the villagers and establish the correct values and non views. At the same time, we should strengthen the publicity of laws and regulations, the popularization of legal knowledge, and use the clear and easy expression to make it aware of the harm of gambling and the illegal consequences of gambling behavior, self-restraint to participate in gambling, and eliminate the further spread of gambling atmosphere from the source. Close up the local complex, the farmer's love for the land is rooted in the heart, so it can carry out the agricultural planting technology and other activities, invite related experts to the village and the villagers face to face exchanges, re 
stimulate their learning enthusiasm, improve the relevant knowledge, let the farmers back to the land, for the follow-up economic construction. Lay a solid foundation for agricultural technology and professional agricultural labor.

\section{Strengthen the construction of grass-roots organizations}

The prevalence of gambling in rural areas and related departments have a direct relationship with the inaction of gambling. Therefore, in order to solve this problem thoroughly, we must strengthen the construction of grass-roots organizations and ensure that the relevant policies can be targeted and practical on the villagers. We should unswervingly adhere to and strengthen the party's leadership in rural work, improve the party's leadership system and laws and regulations in the rural areas, and ensure that the party always takes the overall situation and coordinates the parties in the rural work, and provides strong political guarantee for the Rural Revitalization. To improve the political and legal quality of grass-roots organizations, to eliminate the occurrence of gambling by grass-roots cadres, to strengthen the construction of organization advanced and purity, to implement relevant policies, to strictly enforce laws and regulations, to avoid the improper implementation of policy and not strict legal supervision caused by human factors. We must truly crack down on gambling behavior, fully publicize gambling hazards, and carefully educate gambling people, so that we can really prevent gambling from continuing to grow.

\section{CONCLUSION}

The prevalence of rural gambling culture has a long history, and its reasons also involve geographical, economic, cultural, political and other aspects. It is not possible to achieve a complete solution to a thorough solution. The government and relevant departments need to use hard work and hard work to actively carry out the strategy of Rural Revitalization. According to the actual situation of $X$ village, we should make full use of the existing resources, carry out the concept of green coordinated development, perfect the construction of infrastructure, enrich the supply of cultural market, increase the input of rural education. At the same time, we should give full play to the driving role of the surrounding core cities, promote the $\mathrm{X}$ village to go out of the closed and multi-dimensional, to fundamentally solve the bad habits of the prevailing gambling atmosphere, and truly achieve the prosperity of the industry, the ecological livability, the civilization of the countryside, the effective governance and the prosperity of the country.

\section{REFERENCES}

[1] Wang Yahua, Su Yiqing. Rural Revitalization: a new strategy for China's rural development [J]. Journal of central socialist Institute, 2017 (06): 49-55. (In Chinese)

[2] He Shufang 1 mo Ming Yu. Reasons for the economic and cultural level of rural gambling, [J]. labor security world, 2017, (14). (In Chinese)

[3] Liu Jianfa. On the causes and Countermeasures of rural gambling in the new era [J]. legal system and society, 2008, (22). (In Chinese)

[4] Shen Huizhang, Zhu Haoguang. Gambling problems in rural areas and Their Countermeasures: [J]. Journal of Hunan Police Academy, 2014, (3). (In Chinese)

[5] Jiang Ping. Implementing Rural Revitalization Strategy and drawing lessons from development mode [J]. agriculture economy and management, 2017 (06): 17-24. (In Chinese)

[6] Liu Heguang. Strategic key point of Rural Revitalization and its path [J]. China's national conditions and strength, 2017 (12): 35-37. (In Chinese)

[7] Liao Cairong, Chen Mei ball. The theoretical logic, scientific connotation and realization path of Rural Revitalization Strategy [J]. Journal of agriculture and forestry economic management, 2017,16 (06): 795-802. (In Chinese) 